\title{
Finite Element Analysis and Experimental Study of Metal Shell of GIL
}

\author{
Gong Mimi $^{1 \text {,a }}$, Zhao Yantao ${ }^{1}$, Fu Jiajia ${ }^{2}$, Luo Changlu ${ }^{1}$, Sun Mingdao ${ }^{1}$, Ma Zhiqiang ${ }^{1}$, Shi Fengtao ${ }^{1}$, Gao Zhenkui ${ }^{1}$, Sun \\ Fang $^{1, *}$, Li Zhankui $^{1}$ \\ ${ }^{1}$ State Grid Pinggao Group, Henan Pingzhi High-voltage Switchgear Co., Ltd, Pingdingshan, Henan, 467001, China \\ ${ }^{2}$ State Grid Pinggao Group, Henan Pingao electric Co., Ltd, Pingdingshan, Henan, 467001, China
}

\begin{abstract}
Mathematical modeling, finite element numerical simulation and experimental measurement of the stress-deformation distribution of the gas-insulated metal-enclosed transmission line shell were carried out. Also, Stress linearization analysis was used to analyze the maximum stress. The results show that the stress is linearly dependent on water pressure and the shell occurs elastic deformation without plastic deformation. The simulated maximum stress of $76.2 \mathrm{MPa}$ is fairly in good agreement with the measured one (69.9MPa). The stress linearization analysis results show that the shell well satisfies the environmental safety requirements. The experimental results are consistent with the finite element results.
\end{abstract}

\section{Introduction}

Gas insulated metal-enclosed transmission line(GIL)is a high-voltage and high -current power transmission equipment which uses $\mathrm{SF}_{6}$ gas or $\mathrm{SF}_{6} / \mathrm{N}_{2}$ mixed gas as insulating medium and has a shell with coaxial conductor arrangement. The advantage of GIL is high reliability, large transmission capacity, low loss, safety and environmental protection, convenient installation and maintenance ${ }^{[1-5]}$.At present, as an alternative of overhead transmission line and power cable, GIL is widely used in special transmission environment and large capacity, long distance transmission field ${ }^{[6-8]}$.

The main components of GIL include shell, conductor, epoxy insulator(supporting insulator and disc insulator), sliding contact components, bellows ( expansion joint) and particulate trap ${ }^{[9]}$.As the main component, the mechanical property of the shell directly affects the using effect of GIL. This paper took the rectangular shell for example, established simulation model and calculated stress deformation distributions in finite element method, carried out stress and strain experiment to verify the correctness of design calculation and simulation model.

\section{Stress simulation calculation and analysis}

The rectangular metal shell of GIL is welded by 5052$\mathrm{H} 112$ aluminum alloy plate whose thickness is $10 \mathrm{~mm}$. The material characteristics are as follows: tensile strength $\mathrm{Rm}$ $=195 \mathrm{MPa}$, poisson ratio $\mu=0.33$, modulus of elasticity $\mathrm{E}$ $=70 \mathrm{GPa}$, allowable stress $\mathrm{Sm}=48 \mathrm{MPa}$.

\subsection{Model and Mesh}

As shown below, the rectangular shell model is built in the ANSYS software is connected with plate by bolts. When calculating, it need to consider the influence of bolt pretightening force and O-ring seal on the shell stress. The shell model is divided into 1957705 nodes and 1240890 units, and the mesh are uniform.

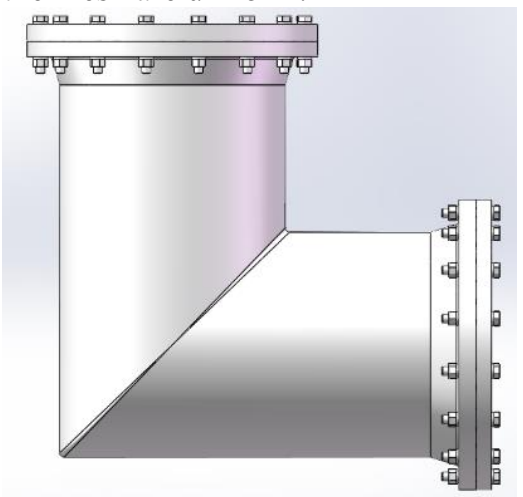

Figure 1. The shell model

\subsection{Load and Boundary condition}

When simulating, the boundary condition is applied to the shell flange and the deflection of which is restrained. Also, the inner surface of the shell is applied by $0.6 \mathrm{MPa}$ internal pressure, the flange is applied by $63631 \mathrm{~N}$ bolt pretightening force and $89237 \mathrm{~N}$ O-ring reaction force. 


\subsection{Linear stress analysis}

Linear stress analysis is carried out on the maximum stress point which starting point is on the outside of shell and ending point is on the inside of the shell. Through the results, local membrane stress, bending stress, bending and membrane stress is analyzed. According to the formula (1) - (4) and the results, stress intensity is approximately calculated.

$$
\begin{aligned}
& \sigma_{m}=\frac{1}{l} \int_{\frac{-l}{2}}^{\frac{l}{2}} \sigma d x \\
& \sigma_{b}=\frac{12 x}{l^{3}} \int_{\frac{-l}{2}}^{\frac{l}{2}} \sigma x d x
\end{aligned}
$$

$\sigma$ is practical nonlinear stress, $\sigma_{m}$ is membrane stress, $\sigma_{b}$ is bending stress, $l$ is section thickness, $x$ is path coordinate.

Linear stress $\sigma_{L}$ is the sum of membrane stress and bending stress, peak stress $\sigma_{p}$ is the difference between practical nonlinear stress and linear stress.

$$
\begin{aligned}
& \sigma_{L}=\sigma_{m}+\sigma_{b} \\
& \sigma_{P}=\sigma-\sigma_{L}
\end{aligned}
$$

\section{Stress strain - hydrostatic experiment}

\subsection{Stress strain electrical measuring method}

When measuring the shell stress, resistance strain gauges are pasted on parts to be tested. Due to the effect of internal water pressure, shell structure will produce deformation that can cause resistance variation and the strain value can be measured by resistance strain gauge. The shell wall which subjected to uniform internal pressure is bidirectional stress state, according to Hook's Law, $X$ direction strain $\varepsilon_{X}$ and $Y$ direction strain $\varepsilon_{Y}$ and corresponding stress value are shown in formula $(5)^{[10-11]}$.

$$
\begin{aligned}
\varepsilon_{x} & =\frac{\delta_{X}}{E}-\mu \frac{\delta_{Y}}{E} \\
\varepsilon_{Y} & =\frac{\delta_{Y}}{E}-\mu \frac{\delta_{X}}{E}
\end{aligned} \longrightarrow\left\{\begin{array}{l}
\frac{E}{1-\mu^{2}}\left(\varepsilon_{x}+\mu \varepsilon_{Y}\right) \\
\frac{E}{1-\mu^{2}}\left(\varepsilon_{x}+\mu \varepsilon_{Y}\right)
\end{array}\right.
$$

\subsection{Stress strain - hydrostatic experiment}

Stress strain - hydrostatic experiment process is as follows:

(1) Shell pretreatment. The test is carried out under no environmental vibration condition, in order to eliminate the effect of welding stress on test results, the shell is filled $0.9 \mathrm{MPa}$ water pressure and maintained more than 12 hours before stress strain test.

(2) Pasting strain gauge. Because the GIL shell is thinwalled pressure vessel, according to stress concentration theory and welding technology, the stress test points should be selected near the shell intersecting line and welding line. This test selects eight points and the position is shown below. The process of pasting strain gauge is as follows: (1) polishing test point bonding plane; (2) marking out bonding position( $\mathrm{X}$ direction, $\mathrm{Y}$ direction); (3)cleaning bonding position; (4) smearing adhesive; (5) pasting strain gauge; 6)adhesive hardening(about $1 \mathrm{~min}$ ); (7)connecting strain gauge to strain gauge meter.

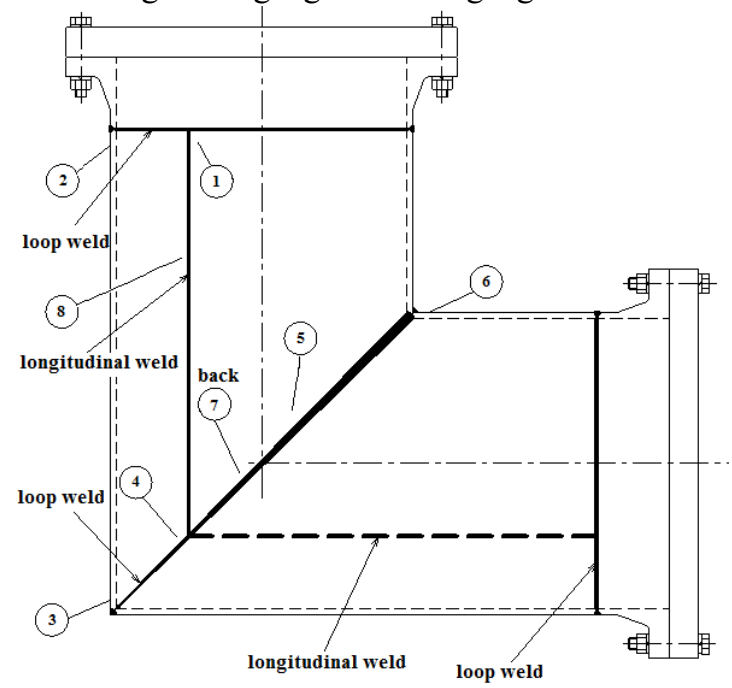

Figure 2. Stress strain test point position

(3) Strain collecting (nondestructive). When testing, the water pressure is applied step by step from zero to $0.78 \mathrm{MPa}$ which is stipulated in standard GB7674-2008 ${ }^{[12]}$. In the process of pressuring, the strain value is recorded when the water pressure is $0.3,0.4,0.5,0.6,0.7,0.78 \mathrm{MPa}$. Also, it should stop pressuring when the water pressure is $0.78 \mathrm{MPa}$. All data should be collected after the water pressure stabilizes and maintains at least $5 \mathrm{~min}$.

(4) Strain collecting (destructive). For further studying the relationship of water pressure and stress, hydraulic failure test is carried out, the water pressure is applied by $10 \%$ step length and the strain value is recorded. when water pressure is $3 \mathrm{MPa}$ ( 5 times design pressure), the shell has not occur destruction and it has entered fully plastic deformation that does not meet Hook's Law and continuing pressuring has no meaning, so the test is terminated and the hydraulic failure test is qualified.

\section{Result and discussion}

\subsection{Finite element analysis}

GIL rectangular shell finite element analysis results are shown in the figure below. Figure (a) and Figure (b) are the stress analysis results outside and inside of shell. The maximum stress is $195.62 \mathrm{MPa}$ which is located outside of upper flange where is flange and its end transition region and exists sharp corner problem. When calculating, the sharp corner exists stress concentration and nonconvergence that can lead the stress is greater than the actual situation, but in practice, this place will be polished smooth and there is no sharp corner problem ${ }^{[13]}$. Beyond that, the maximum stress of the shell is $76.2 \mathrm{MPa}$ which is located at test point 5 and the stress of test point 6 is 65.7MPa. 


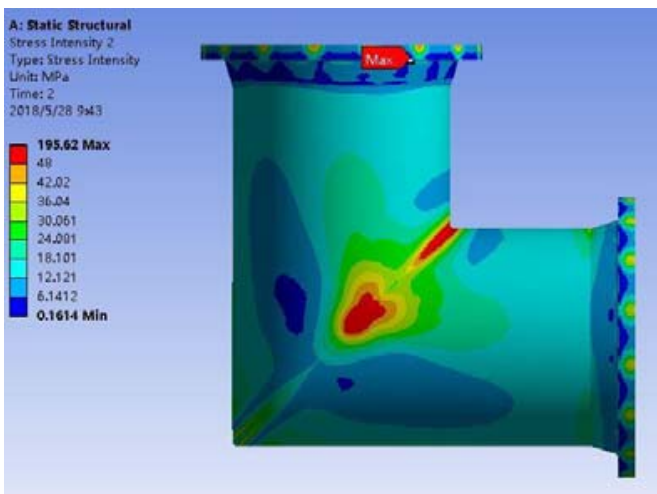

(a) outside

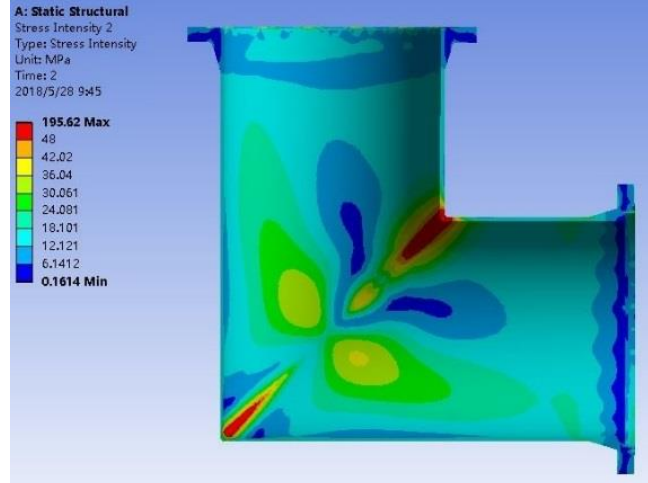

(b) inside

Figure 3. Rectangular shell finite element analysis results

\subsection{Stress linearization analysis}

Stress linearization analysis was used to further analyze the stress of test 5 and test 6 to verify the rationality of the shell design. Stress equivalent linearization path selection

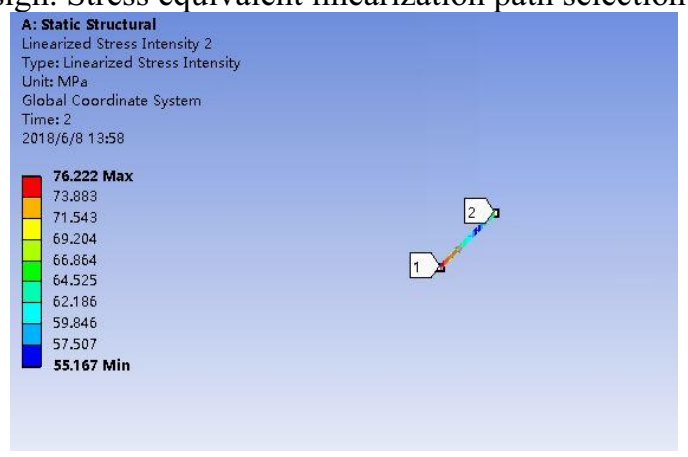

Figure 4. Linearization analysis result of test 5

The stress of above calculation results is actual stress which includes bending stress 、membrane stress and peak stress. when linearization analyzing, the membrane stress 、 bending stress and membrane + bending stress can be extracted respectively, but it does not distinguish primary and secondary stress. According to JB4732, all kinds of allowable stress are as follows: primary general membrane stress $\mathrm{S}_{।} \leq \mathrm{S}_{\mathrm{m}}$, primary local membrane stress $\mathrm{S}_{\|} \leq 1.5 \mathrm{~S}_{\mathrm{m}}$, primary membrane stress + primary bending stress $S_{\|}$ $\leq 1.5 \mathrm{~S}_{\mathrm{m}}$. For security, membrane + bending stress should use the $1.5 \mathrm{~S}_{\mathrm{m}}$ as allowable criterion. The stress of test 5 and test 6 are shown in the table below, as seen from the table, the stress of test 5 and test 6 are less than allowable stress which means the shell stress meet the requirement.

Table 1. Stress linearization analysis results

\begin{tabular}{cccc}
\hline stress & $\begin{array}{c}\text { stress of } \\
\text { test 5 }\end{array}$ & $\begin{array}{c}\text { stress of } \\
\text { test 6 }\end{array}$ & $\begin{array}{c}\text { allowable } \\
\text { stress }\end{array}$ \\
\hline general & 10.139 & 20.977 & $\mathrm{~S}_{\mathrm{m}}=48 \mathrm{MPa}$ \\
membrane & $\mathrm{MPa}$ & $\mathrm{MPa}$ & \\
stress & & & \\
bending stress & 49.549 & 34.915 & - \\
& $\mathrm{MPa}$ & $\mathrm{MPa}$ & \\
membrane + & 58.203 & 49.166 & $1.5 \mathrm{~S}_{\mathrm{m}}=72$ \\
bending stress & $\mathrm{MPa}$ & $\mathrm{MPa}$ & $\mathrm{MPa}$ \\
\hline
\end{tabular}

requirements: (1) pick up two endpoints along the wall thickness as path; (2) the path should be perpendicular to the middle plane of cross section. According to the above way, linearization analysis results of test 5 and test 6 are shown in figure 4 and figure 5.

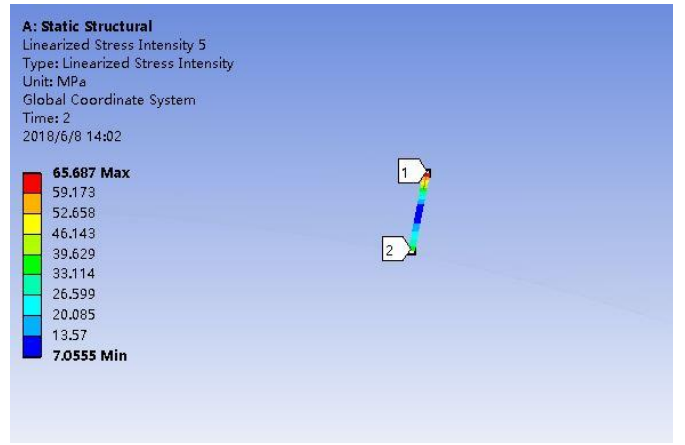

Figure 5. Linearization analysis result

\subsection{Stress strain test result}

When the theoretical design and finite element analysis of GIL rectangular shell are completed, experimental prototype is produced and the stress strain test is carried out to verify the correctness of theoretical design and simulation model. The test attitude of stress strain test is shown in figure6.

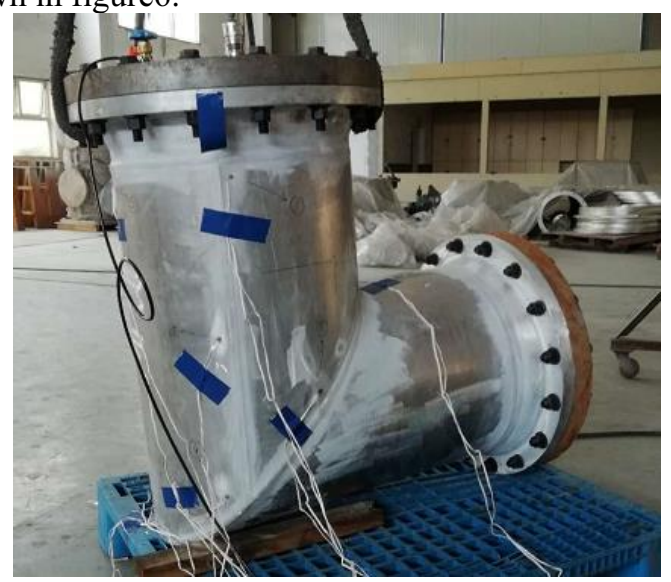

Figure 6. The test attitude of stress strain test

Figure 7 is stress curve of all test points. The test 
results show that the stress of all points is linear related to hydraulic pressure, within the scope of hydraulic pressure, the shell is completely in elastic deformation scope and does not occur yield or permanent deformation. The stress of thin-walled pressure vessel is divided into two kinds: one kind is positive value which means tensile stress, the other kind is negative value which means compressive stress. In addition, as can be seen from the figure, the $X$ direction stress and $Y$ direction stress of test point 5 are all biggest, the stress of test point 6 is less than test point 5 which is consistent with finite element analysis results. Figure 8 is $X$ direction stress and $Y$ direction stress of all test points in standard test pressure. As can be seen from the figure, the stress of test point 5 is biggest and is $69.9 \mathrm{MPa}$ (calculated from $X$ direction stress and $Y$ direction stress) which is close to finite element analysis result and verifies the validity of theoretical analysis. The difference between theoretical analysis and experimental value main occur from ideal model error, discretization error and unavoidable experiment error ${ }^{[14]}$.

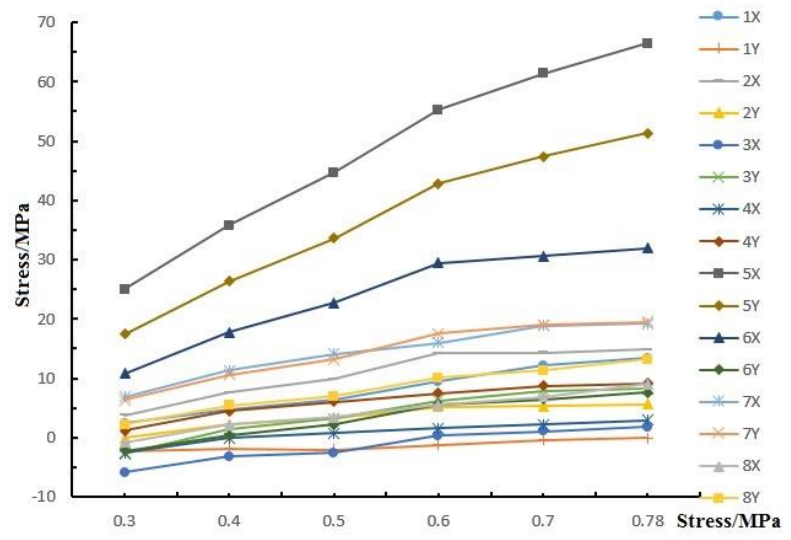

Figure 7. Stress curve of all test points

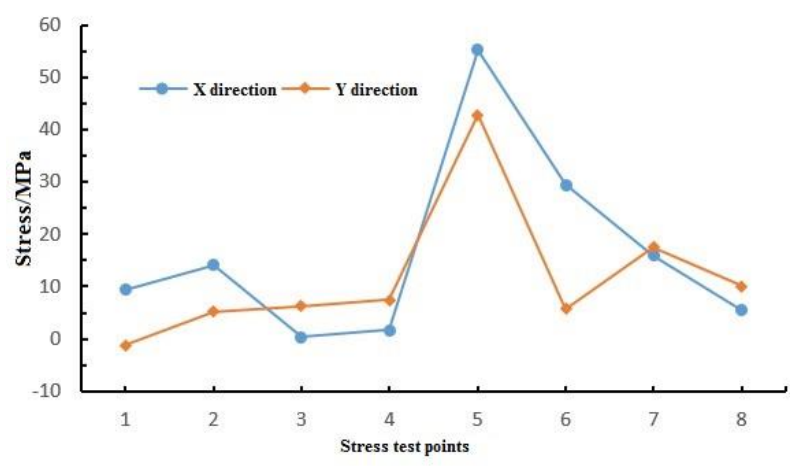

Figure 8. Stress of all test points within test pressure

\section{Conclusion}

(1) Within the scope of test pressure, the relationship of stress and water pressure of all test points has good linearity and the stress increases with the increase of water pressure, which means rectangular shell within $0.78 \mathrm{MPa}$ is in elastic deformation region and does not occur plastic deformation.

(2) According to the first intensity theory, the whole shell mainly suffers from tensile stress and the maximum stress is $69.9 \mathrm{MPa}$ which is located at test point 5. Also, the maximum stress is less than tensile strength and totally meets the design requirement.

(3) After Finite element analysis, stress linearization analysis was used to analyze the stress of test point 5 and test point 6 , the results show the stress of test point 5 and test point 6 are less than allowable stress which meet the design requirement.

(4) The results of finite element analysis are consistent with experimental results. Theoretical biggest stress of point 5 is $76.2 \mathrm{MPa}$ and test measured value is $69.9 \mathrm{MPa}$ which is close to the theoretical value and verifies the validity of finite element analysis.

\section{References}

1. Kochh (2012) Gas insulated transmission lines (GIL), UK: Wiley-IEEE Press, Chichester, 33-38.

2. Fan J.B. (2008) Gas insulated metal enclosed transmission lines (GIL) and its application, Electric Power, 41(8): 38-43.

3. Ruan Q.R., Xie X.P. (2011) Research and practice on engineering design of gas-insulated metal closed transmission lines, China: China Water Power Press, Beijing.

4. Li P., Li Z.B., Sun Q., et al (2015) Research on insulation design of UHV gas-insulated metalenclosed transmission line, Power System Technology, 39(11): 3305-3312.

5. Xiao D.M., Yan J.D. (2017) Application and development of gas insulated transmission line (GIL), High Voltage Engineering, 43(3): 699-707.

6. Qi B., Zhang G.X., Li C.G., et al (2015) Research status and prospect of gas-insulated metal enclosed transmission lines, High Voltage Engineering, 41(5): 1466-1473.

7. Wang H. (2017) Research on key technology of GIL for UHV substation, China Academy of Electric Power Science, Beijing, 169-173.

8. Wang J.G.(2009) Discussion on rigid gas insulated transmission line (GIL) market and technology ,Electrical Industry, 33-36.

9. Hermann K. (2016) Gas-Insulated Transmission Lines, China Machine Press, Beijing, 2016:62-66.

10. Zhang R.Y. (1998) Strain electrical measurement and sensor, Tsinghua University Press, Beijing, 1998: 47 -51 .

11. Sun M.D., Liu X., Ma X.H, et al (2017) Analysis of Stress test of Disconnecting Switch Cast Shell, Special Casting \& Nonferrous Alloys, 37(7):777 780.

12. National Technical Committee for Standardization of High voltage Switchgear. Gas insulated metal enclosed switchgear for rated voltages of $72.5 \mathrm{kV}$ and above (2008), GB7674-2008, China Standards Press, Beijing.

13. Bai H.Y., Fang Y.L. (2014) ANSYS Limit Load Analysis Method in Pressure Vessel Design, Pressure 
Vessel, (01) : $47-50$.

14. Cao Y. (2018) Ansys18.0 Finite Element Analysis from Beginner to Proficient, Electronic Industry Press, Beijing, 2018:11-13. 